\title{
Spinalni epiduralni hematom brez pomembne poškodbe pri otroku
}

\section{Spinal Epidural Haematoma Without Significant Trauma in a Child \\ (1)}

Urška Vračko, Jani Breznik, Mitja

Benedičič, Barbara Faganel Kotnik

\section{Izvleček}

Spinalni epiduralni hematom brez pomembne predhodne poškodbe je nujno stanje, s katerim se $v$ pediatriji srečamo zelo redko. Diagnozo postavimo s kliničnim pregledom in slikovno preiskavo. Zdravljenje je večinoma kirurško. V prispevku predstavljamo spinalni epiduralni hematom pri enajstletnem, do tedaj zdravem dečku, ki je nenadoma začutil bolečino $v$ predelu desne lopatice. Po kliničnem pregledu smo sum na patološko dogajanje v predelu hrbtenice potrdili z magnetnoresonančnim slikanjem. Po kirurški evakuaciji hematoma je deček popolnoma okreval.

Ključne besede: spinalni epiduralni hematom, otrok, bolečina, nevrološki znaki, laminektomija.

\section{Abstract}

Spinal epidural haematoma without significant precedent trauma is an emergency medical condition, which is rarely encountered in paediatrics. The diagnosis is made by clinical examination and imaging. Treatment is generally surgical. In this paper, we present the clinical picture and treatment of spinal epidural haematoma in an eleven-year-old previously healthy boy, who complained of sudden pain in the right shoulder blade area. Clinically, we suspected spinal pathology, which was eventually proven by magnetic resonance imaging. After surgical evacuation of the haematoma, the boy made a complete recovery.

Key words: spinal epidural haematoma, child, pain, neurological signs, laminectomy. 


\section{Uvod}

Spontani spinalni epiduralni hematom (angl. spontaneous spinal epidural haematoma, SSEH) je redko, a nujno stanje (1), pri katerem se $v$ epiduralnem prostoru spinalnega kanala nakopiči kri brez predhodne pomembne poškodbe (2). Ker izraz SSEH zajema tako idiopatski SEH (angl. spinal epidural haematoma, SEH), krvavitve zaradi motnje strjevanja krvi, krvavitve zaradi žilnih malformacij kot tudi krvavitve zaradi predhodne manjše poškodbe $(3,4)$, nekateri strokovnjaki predlagajo poimenovanje SEH brez predhodne pomembne poškodbe $(5,6)$.

Dejavniki tveganja za razvoj SSEH so tumorji, antikoagulantno zdravljenje, prirojene motnje strjevanja krvi, arterijska hipertenzija, arterio-venske malformacije in poškodbe (7). SSEH se najpogosteje pojavi v četrtem in petem desetletju življenja z znaki akutne bolečine $v$ vratu ali hrbtu z zakasnelimi nevrološkimi znaki (2). Pri otrocih je diagnosticiranje oteženo, saj je klinična slika običajno neznačilna, nevrološka ocena pa manj zanesljiva (2).

Za uspešno zdravljenje sta potrebni čimprejšnja prepoznava in $v$ večini primerov tudi kirurška dekompresija (1). Ker gre za izjemno redko stanje, zlasti pri otrocih, je pomembno, da v diferencialnodiagnostičnem naboru vzrokov za bolečino v vratu ali hrbtenici vedno pomislimo tudi na SEH. Ob sumu na SEH je nujno hitro ukrepanje, saj s postavitvijo napačne diagnoze zamudimo pravočasno zdravljenje, kar se odrazi v rasti hematoma (7). Nezdravljeni SEH lahko vodi v paraplegijo in tetraplegijo, opisujejo pa tudi smrtne primere (1).

\section{Prikaz primera}

Enajstletni, sicer zdrav deček je bil rojen $v$ roku po normalno potekajoči nosečnosti. Zjutraj je med gledanjem televizije začutil nenadno bolečino $v$ področju desne lopatice, zato mu je mati dala paracetamol. Dve uri kasneje je opisal mravljinčenje $v$ desnem zgornjem in spodnjem udu, čez dan pa še negotovost pri hoji, zato so ga sprejeli $v$ regionalno bolnišnico. Dan po sprejemu je še vedno navajal bolečine, ki so bile manj izrazite in so po jemanju paracetamola izzvenele pa tudi hoja se je izboljšala in se po dvodnevni hospitalizaciji povsem normalizirala. Laboratorijske preiskave (hemogram, elektroliti, sečnina, kreatinin, transaminaze, bilirubin in encimi mišičnega razpada) so bile $v$ mejah normalnih vrednosti, kazalniki vnetja pa nizki. Ker je specialist fiziater ocenil, da gre za spastično mišično bolečino, ob kateri se lahko pojavi tudi mravljinčenje, so dečka po dveh dneh v izboljšanem stanju odpustili v domačo oskrbo.

Zvečer istega dne ga je iz spanja zbudila bolečina v področju desne lopatice. Po protibolečinskem zdravilu je preostanek noči prespal. Zjutraj se je prebudil pomočen in spet navajal mravljinčenje. Čez dan je opažal šibkost desne strani telesa in težjo hojo, zato ga je dežurni zdravnik regionalne bolnišnice po opravljenem pregledu napotil na Pediatrično kliniko Univerzitetnega kliničnega centra Ljubljana.

Ob sprejemu je bil deček neprizadet brez povišane telesne temperature in dobro razpoložen, navajal pa je bolečine $v$ vratu. Nevrološki status je pokazal izrazito omejeno gibljivost vratu in nakazane pozitivne meningealne znake. $V$ desnem zgornjem in spodnjem udu smo ugotovili zmanjšano aktivno gibljivost in zmanjšanje mišične moči ob ohranjenem tonusu in trofiki. Kitni refleksi na zgornjih in spodnjih udih so bili so živahni in simetrični. Rezultat testa za latentno parezo je bil zaradi desnostranske šibkosti nezanesljiv. Test prst-nos je deček z desnico izvajal upočasnjeno in nenatančno, a brez tremorja, pri tandemski hoji ga je zanašalo, Rombergov preizkus je bil negativen. Hoja je delovala širokotirno in nezanesljivo, hoja po prstih pa je bila normalna. Ob pregledu ni navajal senzibilitetnih izpadov.
Zaradi suma na patološko dogajanje v spinalnem kanalu smo opravili magnetnoresonančno slikanje (MRI) glave in cervikotorakalnega predela hrbtenice, ki je pokazalo utesnitev spinalnega kanala na cervikotorakalnem prehodu, najverjetneje zaradi epiduralnega hematoma $v$ področju med vretencema C5 in Th1 z najbolj iztisnjenim likvorskim prostorom na ravni C6-C7.

Natančna družinska in osebna anamneza nista pokazali prirojenih motenj strjevanja krvi ali slabosti vezivnega tkiva. Izvidi v nočnem času dostopnih presejalnih testov strjevanja krvi, tj. hemograma, protrombinskega časa, parcialnega tromboplastinskega časa, trombinskega časa in fibrinogena, so bili za starost primerni. Pomembnih poškodb, ki bi jih utrpel v dnevih pred sprejemom, njegovi starši niso navedli.

Dečka smo predstavili specialistu nevrokirurgu, ki je še isto noč opravil desnostransko dekompresijsko hemilaminektomijo v področju vretenc C5Th1 in evakuiral epiduralne formacije, ki smo jih naknadno histološko opredelili kot hematom $v$ fazi organizacije. Pred posegom in še nekaj dni po operaciji je prejemal antiedematozno zdravljenje $z$ deksametazonom. Po posegu deček ob rednem jemanju protibolečinskih zdravil ni navajal bolečin in parestezij, vse štiri ude pa je gibal normalno ob blago zmanjšani mišični moči desne roke. Navajal je občutek toplote v področju desnih udov.

Zaradi ne povsem pojasnjene etiologije epiduralnega hematoma smo med hospitalizacijo in tudi po odpustu opravili obširne diagnostične preiskave za izključitev motnje strjevanja krvi ali slabosti vezivnega tkiva, česar nismo dokazali. Naknadno so starši omenili, da je tri dni pred pojavom težav med igranjem nogometa padel vznak na travnato površino.

Peti dan po posegu smo dečka odpustili v domačo oskrbo. Pričel je $z$ intenzivno rehabilitacijo na Univerzitetnem rehabilitacijskem inštitutu Soča. Po zaključenem fizioterapevtskem zdra- 


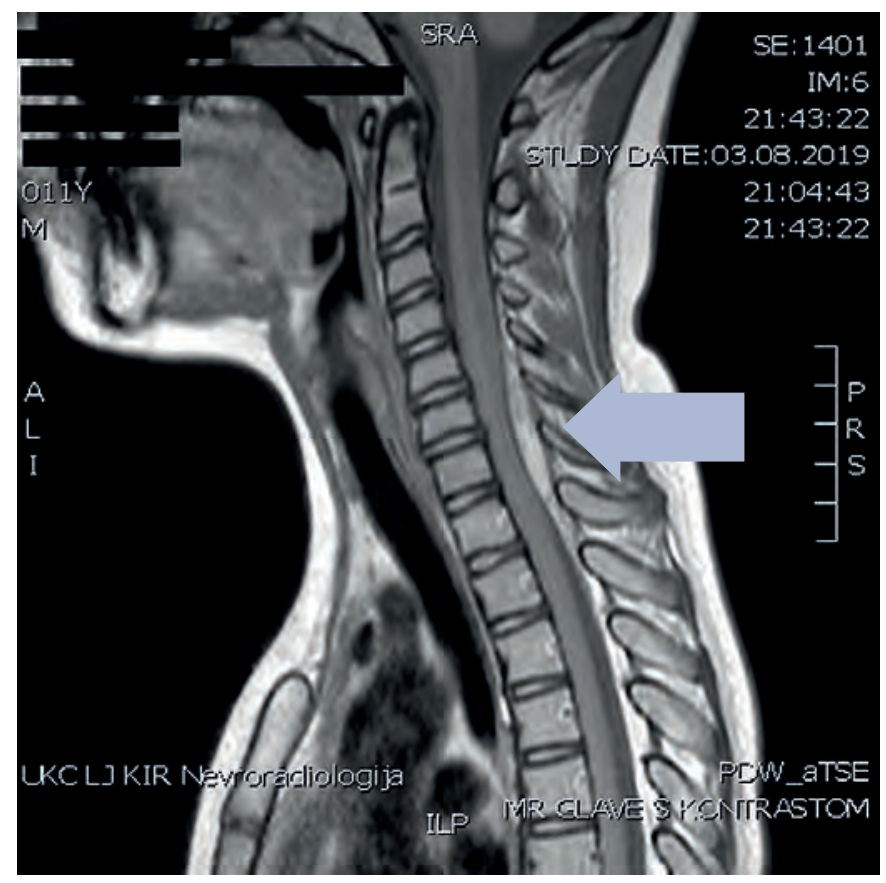

SLIKA 1. SAGITALNI MRI POSNETEK PRED POSEGOM. FIGURE 1. SAGITTAL MRI IMAGE BEFORE SURGERY.

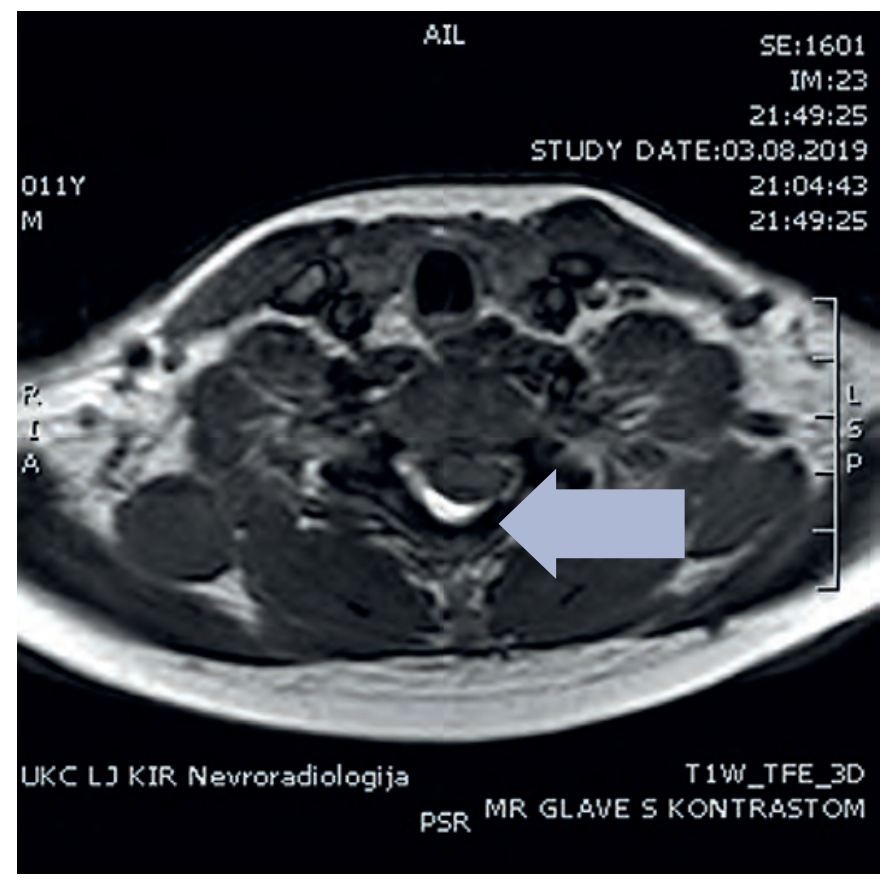

SLIKA 2. TRANSVERZNI MRI PRED POSEGOM. FIGURE 2. TRANSVERSE MRI BEFORE SURGERY. vljenju smo opravili kontrolni pregled nevrološkega stanja. Pareza je izzvenela in prišlo je do popolnega kliničnega izboljšanja, zato smo predlagali postopno uvajanje $v$ športne dejavnosti in svetovali izogibanje hujšim udarcem ter hitrim in sunkovitim gibom. Pol leta po operaciji je deček opravil kontrolno MRI hrbtenice, ki ni pokazala rezidualnih sprememb po posegu in tudi ne znakov žilnih malformacij, zato se za dodatno slikovno diagnosticiranje, tj. računalniškotomografsko angiografijo (CTA) ali digitalno subtrakcijsko angiografijo, nismo odločili.

\section{Razpravljanje}

Epiduralni hematom je kolekcija krvi med duro mater in kostjo. Topografsko epiduralne hematome delimo na znotrajlobanjske in spinalne. Znotrajlobanjski hematomi se običajno pojavijo po poškodbi glave in so lahko akutni, subakutni ali kronični (8). Etiološko SEH delimo na travmatske, iatrogene (kot posledica posegov v tem predelu, npr. zaradi lumbalne punkcije, epiduralne anestezije) in spontane (9). Ker izraz spontani SEH zajema tako idiopatski SEH, krvavitve zaradi motnje strjevanja krvi in žilnih malformacij kot tudi krvavitve zaradi predhodne manjše poškodbe $(3,4)$, nekateri strokovnjaki predlagajo, da poimenovanje SSEH opustimo in tovrstno krvavitev poimenujemo SEH brez predhodne pomembne poškodbe $(5,6)$.

SEH brez pomembne predhodne poškodbe predstavljajo manj kot $1 \%$ vseh sprememb, ki jih ugotovimo v spinalnem prostoru $(8,9)$. Letno pojavnost $v$ splošni populaciji ocenjujejo na en primer na milijon prebivalcev (9), pri otrocih pa naj bi bila še nižja. Pri otrocih se običajno pojavi v cervikotorakalnem predelu, krvavijo pa najpogosteje iz ven (10).

$\checkmark$ opisanem primeru smo med pooperativnim spremljanjem ugotovili, da je deček tri dni pred pojavom kliničnih znakov utrpel blažji udarec ob padcu na travo vznak, zato morebitnega vpliva blage poškodbe ob padcu na razvoj hematoma ne moremo z zagotovostjo izključiti. Glede na pogostost podobnih lažjih poškodb pri otrocih in izredno malo primerov SEH lahko krvavitev $v$ opisanem primeru uvrstimo med SEH, ki se razvijejo brez pomembne poškodbe pred pojavom znakov.

Klinična slika običajno nastopi nenadno. Značilna je akutno nastala bolečina v predelu vratu ali hrbta, ki se lahko širi navzdol v spodnje ude. Pridružijo se lahko nevrološki simptomi, od blagega mravljinčenja do popolne hemipareze, in so posledica okvare spodnjega motoričnega nevrona s hiporefleksijo in flakcidno paralizo (11). Pogosto so $v$ ospredju tudi netipični simptomi in znaki, tj. razdražljivost, jokavost in tortikolis s povišano telesno temperaturo ali brez nje, kar lahko zmotno napelje na diagnozo meningitis $(3,10,11-15)$. Pri mlajših otrocih pogosto ugotavljamo tudi zastajanje seča, pri starejših otrocih pa je najbolj značilna dobro umeščena bolečina $v$ vratu ali ledveno (11). Nevrološki simptomi lahko nastopijo tudi $z$ večurno do nekajdnevno zakasnitvijo (6). Pri opisanem prime- 


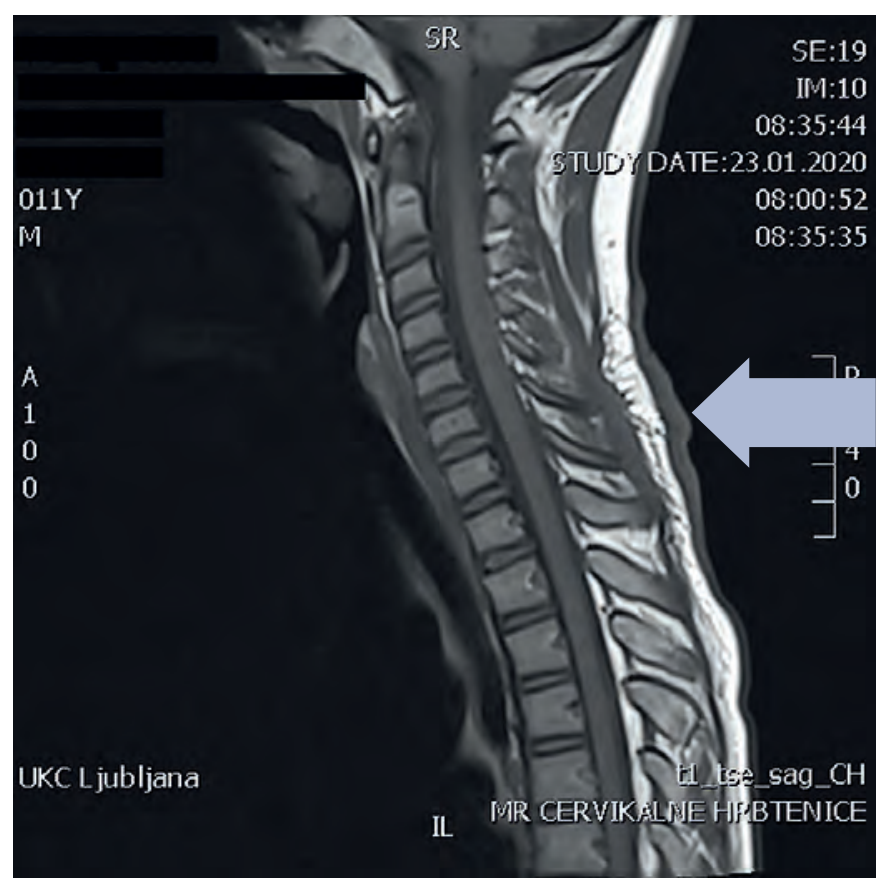

SLIKA 3. SAGITALNI MRI POSNETEK PO POSEGU. FIGURE 3. SAGITTAL MRI IMAGE AFTER SURGERY.

ru so se nevrološki simptomi spreminjali in lažno nakazovali izboljšanje še neopredeljenega stanja.

Z MRI smo kot vzrok težav izključili primarne tumorje hrbtenjače (npr. astrocitom), primarne kostne tumorje vretenc (npr. osteosarkom, osteoblastom), metastatske tumorje (levkemija, nevroblastom, limfom), tranzverzni mielitis, epiduralni absces in spondilolistezo.

V stopenjskem diagnosticiranju lahko opravimo rentgensko slikanje za izključitev zlomov vretenc (11). Ob nejasnih primerih in sumu na okužbo osrednjega živčevja je na mestu tudi lumbalna punkcija, ki pa ni povedna in pogosto pokaže le zvišano vrednost beljakovin (16). Zlati diagnostični standard je MRI hrbtenice, ki prikaže mesto in velikost hematoma ter tudi morebitno utesnitev hrbtenjače in znake edema (17). CT-angiografijo uporabljamo v nejasnih primerih in ob sumu na žilne malformacije, od katerih so najpogostejše arterio-venske malformacije $(6,10)$.
Ob nepojasnjeni etiologiji je smiselno izključiti vezivnotkivne bolezni in motnje strjevanja krvi. Znani so opisi SSEH pri bolnikih s pomanjkanjem faktorja VIII (hemofilija A), faktorja IX (hemofilija B) (18) ter faktorja XI (hemofiija C). Zato smo pri dečku v opisanem prikazu primera izključevali tudi prirojeno ali pridobljeno motnjo strjevanja krvi s presejalnimi in z obširnimi usmerjenimi laboratorijskimi preiskavami (zapiralni čas, določitev aktivnosti faktorjev XI, IX, VIII, VII, X, V, II, I, XIII, antigena in aktivnosti von Willebrandovega faktorja (vWF), agregometrija in lumiagregometrija) ter z molekularnogenetsko preiskavo, tj. sekvenciranjem naslednje generacije (angl. next generation sequencing, NGS). Motnje strjevanja krvi nismo potrdili.

Zdravljenje SEH je najpogosteje kirurško z nujno dekompresijo hrbtenjače z laminektomijo. Čeprav je laminektomija trenutno metoda izbire zdravljenja, pa se moramo zavedati, da lahko prekinitev lamine pri nekaterih otrocih zavira normalen razvoj mišic in kosti hrbtenice ter dolgoročno vodi v razvoj kifoze, skolioze ali ukleščenje živčnih struktur (19). V našem primeru smo opravili le hemilaminektomijo. Odstranili smo samo polovico lamine, ohranili pa trnaste odrastke in narastišča mišic na drugi strani pristopa. Zato se je mišično-ligamentni aparat med operacijo le malo poškodoval in ohranila stabilnost hrbtenice, manjša pa je tudi verjetnost kasnejših zapletov.

Če ima bolnik s SEH motnjo strjevanja krvi, moramo najprej poskrbeti za odločno nadomestno zdravljenje s faktorji strjevanja krvi oz. drugimi krvnimi pripravki pred operacijo in po njej. O operaciji se odločimo glede na izraženost nevroloških simptomov. Kirurška odstranitev hematoma je pomembna predvsem zaradi preprečevanja nevroloških posledic. Če ima otrok motnjo strjevanja krvi in res zelo majhen hematom brez hujših nevroloških znakov, je sprva smiselno poskusiti s konzervativnim nadomestnim zdravljenjem s faktorji strjevanja krvi $(19,20)$. Pri osebah z motnjo strjevanja krvi obstaja namreč nevarnost, da se bo hematom zaradi nezadostne hemostaze 
povečeval in povzročil hujše nevrološke simptome, kar lahko pomeni slabši izid zdravljenja, najverjetneje pa tudi potrebo po nujnem kirurškem posegu (21). Zato je nujno odločno nadomestno zdravljenje s koagulacijskimi faktorji oz. drugimi krvnimi pripravki do popolnega izginotja hematoma.

Izid zdravljenja je odvisen predvsem od prvotnega obsega nevrološke okvare. Bolniki s hujšimi nevrološkimi simptomi bodo kljub pravočasnemu odločnemu zdravljenju najverjetneje imeli več trajnih nevroloških posledic (10).

$\mathrm{Na}$ izid zdravljenja prav tako vplivata velikost hematoma in čas, ki je pretekel od postavitve diagnoze do operacije. Pri otrocih je ta meja zabrisana, ker pogosto kljub hujšim simptomom na začetku diagnosticiranja ali kljub zakasnitvi ustreznega zdravljenja hitreje in bolje okrevajo kot odrasli. Tudi v opisanem primeru je prišlo zaradi neprepoznane bolezni do zakasnitve pričetka zdravljenja. Ob potrjenem SEH smo nujno zdravljenje izvedli takoj, tj. že v 6 urah po prihodu v terciarno bolnišnico. Tudi izid je bil za bolnika optimalen. Napovedni dejavniki za slabši izid zdravljenja so poleg prej navedenih tudi prisotnost koagulopatije, hematom, ki se razteza čez več vretenc, in disfunkcija hrbtenjače, ki je bila prisotna pred operacijo (10). Po podatkih iz literature po spinalnem epiduralnem hematomu popolnoma okreva $65,5 \%$ otrok, podatkov za SSEH pa žal v literaturi ni. Smrtnost zaradi SEH v splošni populaciji ocenjujejo na $2 \%$ (6).

\section{Zaključek}

SEH brez predhodne pomembne poškodbe je sicer redko stanje, a je lahko usodno, če ga ne prepoznamo pravočasno. Zato je ob akutni bolečini v vratu in/ali tortikolisu ob odsotnosti povišane telesne temperature ter ob spremljajočih nevroloških znakih tudi ob odsotnosti jasne poškodbe $v$ anamnezi potrebno s slikovno preiskavo izključiti morebitno bolezensko stanje v spinalnem kanalu in odločno ukrepati.
Literatura

1. Zhong W, Chen H, You C, Li J, et al. Spontaneous Spinal Epidural Hematoma. J Clin Neurosc 2011; 18: 1490-4.

2. Kim M, Hoffman J, Amin A, Purohit M, et al. Spontaneous Spinal Epidural Hematoma in an Infant. Pediatr Emerg Care 2018. Dosegljivo na: https://pubmed.ncbi.nlm.nih. gov/29489605/?from_term=spontaneous+spinal+epidural+haematoma+in+children\&from_ pos $=1$.

3. Patel H, Garg BP. Increasing irritability with sudden onset of flaccid weakness. Semin Pediatr Neurol 1996; 3: 192-7.

4. Tewari MK, Tripathi LN, Mathuriya SN, Khandelwal N, et al. Spontaneous spinal extradural hematoma in children. Report of three cases and a review of the literature. Childs Nerv Syst 1992; 8: $53-5$.

5. Domenicucci M, Mancarella C, Santoro G, Dugoni DE, et al. Spinal epidural hematomas: personal experience and literature review of more than 1000 cases. J Neurosurg Spine 2017; 27(2): 198-208

6. Carlhan-Ledermann A, Laubscher B, Steinlin $M$, Ulrich $C T$, et.al. Spinal epidural hematoma without significant trauma in children: two case reports and review of the literature. BMC Pediatr 2020; 20: 77

7. Ratre S, Yadav Y, Choudhary S, Parihar V. Spontaneous ventral spinal epidural haematoma in a child: A case report and review of literature. J Neurosci Rural Pract 2016; 7: 297-99.

8. Liebeskind SD. Epidural Hematoma. 2018. Dosegljivo na: https://emedicine.medscape.com/ article/1137065-overview.

9. Soltani S, Nogaro MC, Rougelot C, Newell N, et al. Spontaneous spinal epidural haematoma in children. Eur Spine J 2019; 28: 2229-36.

10. Jumani DB, Littlewood R, Iyer A, Fellows G, et al. Spontaneous spinal epidural haematoma mimicking meningitis in a 2-year old child - a case report and literature review. Childs Nerv Syst 2013; 29: 1795-8.

11. Figueroa J, DeVine JG. Spontaneous spinal epidural hematoma: literature review. J Spine Surg 2017; 3: 58-63.

12. Chang CW, Lin LH, Liao HT, Hung KL, et al. Spontaneous Spinal Epidural Hematoma in a 5-year-old Girl: Case Reports. Acta Paediatr Taiwan 2002; 43(6): 345-7.

13. Patel H., Boaz J.C., Phillips J.P., Garg B.P. Spontaneous Spinal Epidural Hematoma in Children. Pediatr Neurol 1998;19(4):302-7.

14. Khursheed N, Makhdoomi R, Tanki H, Wani A. Spinal Epidural Hematomas in Fast Bowlers Report of Two Unusual Cases. Pediatr Neurosurg 2013; 49: 303-6.

15. Agha BS, Tehan C, Perno J. Torticollis, Not Always the Usual Suspects. Pediatr Emerg Care $2011 ; 27(1): 32-3$.

16. Schoonjans A, De Dooy J, Kenis S, Menovsky $\mathrm{T}$, et al. Spontaneous spinal epidural hematoma in infancy: Review of the literature and the "seventh" case report. Eur J Paediatr Neurol 2013; 17: 537-42

17. Abdurrahman A, Ozdemir S, Arslan H, Gonullu E, Bozkina C. Idiopathic Thoracic Spontane- ous Spinal Epidural Hematoma. Case Rep Surg 2016. Dosegljivo na: https://www.hindawi.com/ journals/cris/2016/5430708/.

18. Afshari FT, Parikh D, Petrik V. Spontaneous Spinal Epidural Haematoma Secondary to Autoimmune Acquired Haemophilia. Case Rep Neurol 2019; 10: 353-6.

19. Arya A, Jain P, Kumar A, Gulati S. Spontaneous Spinal Epidural Hematoma in an Infant. J Child Neurol 2012; 27: 1577-9.

20. Munoz Gonzales A, Cuello JP, Rodriguez Cruz PM, et al. Spontaneous Spinal Epidural Haematoma: a Retrospective Study of a Series of 13 Cases. Neurologia 2015; 7: 393-400.

21. Gopalkrishnan CV, Dhakoji A, Nair S. Spontaneous cervical epidural hematoma of idiopathic etiology: Case report and review of literature. J Spinal Cord Med 2012; 35: 113-7.

\section{Urška Vračko}

Splošna bolnišnica dr. Franca Derganca« Nova Gorica, Nova Gorica, Slovenija

\section{Jani Breznik}

Zdravstveni dom Slovenska Bistrica, Slovenska Bistrica, Slovenija

\section{Matevž Benedičič}

Klinični oddelek za nevrokirurgijo, Kirurška klinika, Univerzitetni klinični center Ljubljana, Ljubljana, Slovenija

\section{Barbara Faganel Kotnik}

(kontaktna oseba / contact person) Klinični oddelek za otroško hematologijo in onkologijo, Pediatrična klinika, Univerzitetni klinični center Ljubljana, Ljubljana, Slovenija e-naslov: barbara.faganel@kclj.si

prispelo / received: 20. 12. 2020 sprejeto / accepted: 18. 4. 2021

Vračko U, Breznik J, et.al. Spinalni epiduralni hematom brez pomembne poškodbe pri otroku. Slov Pediatr 2021; 28(2): 98-102. https://doi. org/10.38031/slovpediatr-2021-2-05. 